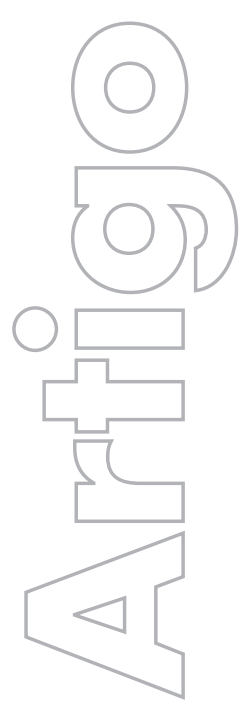

revista

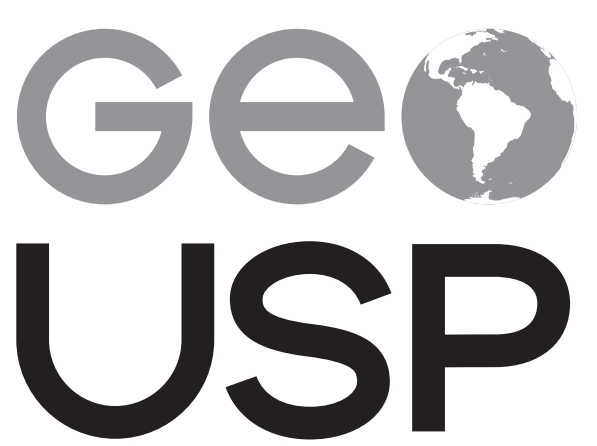

espaço e tempo

Volume $21 \cdot n^{\circ} 3$ (2017)

ISSN 2179-0892
Gentrificação, preservação patrimonial e turismo: os novos sentidos da paisagem urbana na renovação das cidades

Maria Tereza Duarte Paes

Unicamp

p. 667-684

Como citar este artigo:

PAES, M. T. D. Gentrificação, preservação patrimonial e turismo: os novos sentidos da paisagem urbana na renovação das cidades. Geousp - Espaço e Tempo (Online), v. 21, n. 3, p. 667-684, dez. 2017. ISSN 2179-0892.

Disponível em: <http://www.revistas.usp.br/geousp/ article/view/128345> . doi: 10.11606/issn.2179-0892. geousp.2017.128345.

\section{(c) (i) \$)}

Este artigo está licenciado sob a Creative Commons Attribution 4.0 License. 


\title{
Gentrificação, preservação patrimonial e turismo: os novos sentidos da paisagem urbana na renovação das cidades $^{1}$
}

\section{Resumo}

A gentrificação constituiu-se em um processo de natureza dinâmica, seja em sua concepção conceitual ou em sua forma de expressão no espaço. Desde os anos 1990, a preservação de sítios históricos urbanos no Brasil e na América Latina serviu de âncora para a refuncionalização turística e a ascensão econômica de inúmeras cidades, articulou-se às estratégias políticas e econômicas de renovação urbana e ganhou inúmeras denominações a partir de visões teóricas ou técnicas, interesses políticos e escalas diferenciadas. Esses temas serão abordados aqui a partir de apontamentos de pesquisa teórico-conceitual e de argumentos empíricos de algumas cidades brasileiras e centros históricos da América Latina, fundamentando a reflexão sobre a gentrificação global e os seus processos inerentes de injustiça social na produção de novas paisagens e na apropriação seletiva do espaço urbano.

Palavras-chave: Gentrificação. Patrimonialização. Refuncionalização turística. Renovação urbana. Paisagem urbana.

\section{Gentrification, heritage preservation and tourism: the new meanings of urban landscape in the renewal of cities}

\begin{abstract}
Gentrification constitutes itself as a process of dynamic nature, either in its conceptual notion, or in its form of expression in space. Since the 1990s, the preservation of historical urban sites in Brazil and Latin America has served as an anchor for the tourist refunctionalization and economic rise of numerous cities, it has been articulated to the political and economic strategies of urban renewal, and it has gained numerous denominations from theoretical or technical visions, political interests and differentiated scales. These themes will be approached in this
\end{abstract}

A autora foi Bolsista Produtividade CNPq. 
article from theoretical-conceptual research notes and empirical arguments of some Brazilian cities and historical centers of Latin America, grounding the reflection on global gentrification and its inherent processes of social injustice in the production of new landscapes and in the selective appropriation of urban space.

Keywords: Gentrification. Patrimonialization. Tourism refunctionalization. Urban renewal. Urban landscape.

\section{Introdução}

A patrimonialização de sítios históricos urbanos encontrou no atual uso turístico a contraditória e inevitável renovação das cidades ${ }^{2}$. Ao mobilizar o imaginário social e suas representações sobre as paisagens históricas, o planejamento urbano concilia a preservação patrimonial à renovação. As intervenções modernizantes no tecido urbano, a gentrificação, os novos equipamentos e usos sociais, particularmente os turísticos, associam-se à preservação do patrimônio histórico, e todos compõem, agora, a mesma narrativa urbana.

Essa nova trama narrativa é expressa formalmente por um tecido urbano desenhado por rugosidades (Santos, 1996) de edificações antigas justapostas aos modernos equipamentos da paisagem urbana renovada. Por meio da hibridação de materiais, de estéticas, estilos e técnicas, assim como pelos usos, sentidos, representações e intencionalidades dos inúmeros processos de gentrificação, encontramos o que Smith (2006, p. 59) denominou "novo urbanismo", interpretado por Zukin (2000) como paisagens pós-modernas.

$\bigcirc$ conceito de gentrificação (gentrification), criado pela socióloga Ruth Glass em 1964 , foi utilizado pela primeira vez para analisar a transformação imobiliária ocorrida em bairros londrinos que definiu a elitização dos estratos sociais (a alta burguesia urbana - urban gentry) que se apropriaram dos bairros operários. Após a adoção do termo por inúmeros autores e a deflagração dessa estratégia de intervenção urbana em inúmeras cidades em todo o mundo, os processos socioespaciais a ela inerentes passaram a ser mais estudados: a inversão privada de capital para a criação de novos espaços destinados ao comércio, aos serviços e às moradias; a atração dos grupos sociais de alto poder aquisitivo; a expulsão ou a remoção de grupos sociais populares; a especulação imobiliária e o aumento do preço do solo; a expansão do consumo cultural; a dissolução e a recriação de traços identitários associados ao lugar; a gentrificação simbólica (Martí-Costa; Durán; Marulanda, 2016, p. 131) do patrimônio cultural; as políticas e os mecanismos de facilitação dos investidores privados; a atividade turística como estratégia econômica e competitiva entre as cidades.

2 Embora a renovação urbana já apareça no final do século XIX e no início do XX, seja com Hausmman, em Paris, ou Pereira Passos, no Rio de Janeiro, tais intervenções foram ganhando novos significados. Em meados do século $\mathrm{XX}$, enquanto os europeus decidiram preservar ou reconstruir o que restou dos seus patrimônios arrasados durante a Segunda Guerra Mundial, os americanos foram por outra via, a da destruição criativa, ou seja, demolir e construir para renovar, seguindo os princípios da Carta de Atenas (IPHAN, 1933) e dos modernistas (Paes; Silva, 2016, p. 345). Na América Latina, as intervenções modernizantes destruíram grande parte das edificações históricas, salvo os conjuntos patrimonializados ou esquecidos pela modernização urbana e industrial. Apenas após os anos 1970/1980 o patrimônio histórico arquitetônico ganhou valor comercial e políticas de preservação mais abrangentes. Neste artigo, trataremos desta última forma. 
A gentrificação constituiu-se em um processo de natureza dinâmica, seja em sua concepção conceitual, seja em sua forma de expressão no espaço, reveladora dos conflitos sociais de apropriação dessas novas paisagens urbanas. Para Zukin (2000, p. 84), "a paisagem dá forma material a uma assimetria entre o poder econômico e o cultural". A paisagem impõe uma visão estética e também uma intenção, um poder. É uma ordem socioespacial que toma forma como arranjo concreto e simbólico. A paisagem pode ser vista como símbolo do capitalismo (Jameson, 1996) ou como capital do simbolismo (Zukin, 2000), campo de disputas e mediações econômicas, políticas e culturais.

Desde os anos 1990, a preservação de sítios históricos urbanos no Brasil e na América Latina serviu de âncora para a refuncionalização turística (Paes, 2012) e a ascensão econômica de inúmeras cidades. Tal processo articulou-se às estratégias políticas e econômicas de renovação urbana, ganhando inúmeras denominações a partir de visões teóricas ou técnicas, interesses políticos ou escalas diferenciadas, como: enobrecimento, requalificação, reabilitação, revitalização e, o mais emblemático, controverso e duradouro: gentrificação. Ao longo das últimas décadas, tal processo articulou patrimônio cultural, turismo e renovação urbana, tema abordado aqui a partir de apontamentos de pesquisa teórico-conceitual e argumentos empíricos de centros históricos da América Latina.

Iniciado nos países ricos e industrializados nos anos 1970, esse processo recuperou as áreas centrais urbanas abandonadas pelo declínio da industrialização e foi, aos poucos, replicado na escala mundial entre países pobres e ricos, do Norte e do Sul, em cidades grandes e pequenas, todas em busca da reincorporação das áreas centrais à economia política das cidades. Esse novo urbanismo, iniciado em algumas cidades norte-americanas como Nova York, Boston, Baltimore e Portland, e em cidades europeias como Londres, Paris e Berlim, espraiou-se até encontrar o que, na análise de Smith (2006), a partir de Nova York, alcançou uma gentrificação generalizada. A preocupação inicial com a habitação nas áreas centrais degradadas deu lugar a uma nova forma de pensar a paisagem urbana, o urbanismo, o emprego, o consumo e o lazer. A gentrificação incluiu um campo de disputa teórica dos mais férteis em Geografia Humana, pois evidencia "oposições entre estrutura e ação, produção e consumo, capital e cultura, oferta e demanda" (Hamnett, 1991, p. 174).

Ao lembrar o tradicional empreendedorismo privado dominante na produção do espaço urbano nos EUA, Hall (2002[1988]) afirma que o processo de revitalização urbana iniciado no cais de Baltimore e na orla marítima de Boston já trazia as sementes do novo modelo que se espraiaria pelo mundo, incluindo a parceria criativa entre os governos municipais, o nacional e a iniciativa privada. Além disso, ressalta: "Suas bases são despudoradamente turísticas, [o que] fornece a chave decisiva que explica a natureza revolucionária de tais urbanizações" (p. 415).

Esse processo se acentuou nos anos 1990 e "se difundiu geograficamente de Tóquio a Tenerife, de São Paulo a Puebla e México, da Cidade do Cabo às ilhas do Caribe, de Xangai a Seul" (Smith, 2006, p. 62). Com a expulsão dos sem-teto e de outros moradores indesejáveis, ou dos usuários não solventes de Borja e Castells (1996), a gentrificação produziu a paisagem urbana como uma nova mercadoria valorizada, quer para moradia, como ocorreu inicialmente nos países ricos, quer apenas para o lazer e o consumo turístico, como na maioria dos países periféricos, a partir dos anos 1990. Hall (2002[1988], p. 407) se questiona sobre essa reestru- 
turação do planejamento urbano: "Houve um momento, no decorrer da década de 1970, em que o movimento urbanístico começou a plantar bananeira e a virar do avesso [...]. $\bigcirc$ planejamento convencional, a utilização de planos e regulamentos para guiar o uso do solo pareciam cada vez mais desacreditados". Mesmo considerando que esse planejamento racionalista não acabou, afirma que esse novo modelo trouxe de volta um antigo problema social: "a ralé urbana, que lá está, massa mal-humorada e inamistosa, à espera do lado de fora dos portões" (Hall, 2002[1988], p. 427).

De qualquer modo, "a gentrificação como estratégia urbana global” (Smith, 2006, p. 73) passou a ser a orientação para o novo urbanismo. As paisagens urbanas abandonadas da desindustrialização foram substituídas pelas paisagens revitalizadas - como tentou impor o discurso oficial da requalificação, desde as suas primeiras referências norte-americanas.

Claro que esse novo urbanismo, associado às políticas neoliberais e à globalização econômica e cultural dos anos 1990, tomou como referência o Planejamento Estratégico desenhado para a renovação urbanística de Barcelona, que, ao buscar superar a crise de sua economia industrial, encontrou, na preparação para os Jogos Olímpicos de 1992, a articulação de uma nova forma de fazer a gestão e o planejamento urbano com o que ficou conhecido como Modelo Barcelona - replicado à exaustão até hoje, em conceito ou aos fragmentos, como pudemos ver em sua última versão na cidade do Rio de Janeiro, por ocasião dos Jogos Olímpicos de 2016, no Brasil.

Em Barcelona, com financiamento do poder local, da administração pública regional (Generalitat de Catalunya), do Governo Central Espanhol, da Comunidade Europeia e de vários segmentos de setores privados, essa nova e complexa rede de instituições criou uma nova forma de gestão do planejamento urbano que, associada à construção da imagem internacional da cidade, passou a replicar o seu modelo para o mundo. Borja e Castells (1996, p. 153), consultores e referências importantes do planejamento urbano estratégico de Barcelona, afirmaram:

La promoción de la ciudad hacia el exterior que desarrolhe uma imagen fuerte y positiva apoyada en una oferta de infraestructuras y de servicios (comunicaciones, económicos, culturales, seguridad, etc) que atraiga inversores, visitantes y usuarios solventes a la ciudad y que facilite sus "exportaciones" (de bienes y servicios, de sus profesionales, etc).

A cidade, posicionada agora em uma rede empresarial globalizada, compete por investimentos e fluxos de capital. Nessa nova ordem, a força da imagem construída e divulgada por meio da seleção e da renovação da paisagem urbana ganha papel de destaque, pois o "consumo visual é inseparável das estruturas centralizadas do poder econômico" (Zukin, 2000, p. 84).

Para Vainer (2000, p. 82), nesse novo modelo, "a miséria é estrategicamente redefinida como problema paisagístico (ou ambiental)". A fetichização da renovada paisagem urbana encobre descaradamente os processos de segregação socioespacial e os seus sujeitos indesejáveis. Enquanto o Estado do urbanismo progressista, de até meados do século XX, assentado nos paradigmas da produção fordista (racionalidade, funcionalidade, regularidade, produtividade, produtos estandartizados e centralidade do Estado), em uma política econômica keynesiana e em políticas de previdência social, buscava dar conta da totalidade social e urbana, a cidade 
pós-moderna do planejamento estratégico copia as palavras de ordem da lógica empreendedora das empresas (gestão, produtividade, competitividade, bens distintivos de classe, estetização, subordinação dos fins à lógica do mercado, parcerias público-privadas) e produz uma cidade fragmentada, simbólica, colocando-a no mercado como uma mercadoria.

As primeiras, inspiradas em formas, conceitos, materiais (concreto, ferro e vidro), tecnologias e imaginário da cidade industrial, produziram paisagens urbanas que remetiam ao modelo de container das fábricas e à esteira fabril da produção industrial (habitações padronizadas em conjuntos habitacionais, cidades-jardins, vilas operárias, a centralidade dos monumentos institucionais vinculados aos feitos do Estado); as segundas buscam produzir bens simbólicos segmentados e espaços liminares que transgridem as identidades puras: condomínios/comunidades, edifícios antigos/modernos, estruturas flexíveis e arquiteturas emblemáticas, tecnologias para produção de simulacros culturais ou de natureza, renovação/preservação, espaços públicos/privados, identidades encenadas... Nas palavras de Zukin (2000, p. 82): "O espaço incita e imita a ambiguidade. Os sítios específicos da cidade moderna são transformados em espaços liminares pós-modernos, que tanto falseiam como fazem a mediação entre natureza e artefato, uso público e valor privado, mercado global e lugar específico".

O urbanismo contemporâneo não esconde o abandono da narrativa social e a sua substituição pela simulação das formas, da cultura e da história. Essas são encenadas nas fachadas dos conjuntos paisagísticos e disfarçadas no discurso ambiental ensaiado da inclusão social das abstratas gerações futuras. Para Harvey (1992, p. 42), o modernismo dos anos após a Primeira Guerra Mundial ainda tinha algo de heroico:

Na arquitetura, por exemplo, as ideias do CIAM [Congresso Internacional de Arquitetura Moderna], de Le Corbusier e de Mies van der Rohe tinham a primazia na luta para revitalizar cidades envelhecidas ou arrasadas pela guerra (reconstrução e renovação urbana), reorganizar sistemas de transporte, construir fábricas, hospitais, escolas, obras públicas de todos os tipos e, por último, mas não menos importante, construir habitações para uma classe trabalhadora potencialmente inquieta.

Os pilares que sustentavam o urbanismo racionalista, ainda que sob uma concepção autoritária e normativa, apoiavam-se nos ideais progressistas, nas verdades científicas e em um anseio - até certo ponto ingênuo e romântico - de dar conta da totalidade social. Por isso, afirma Harvey (1992, p. 42), "o modernismo resultante era 'positivista, tecnocêntrico e racionalista' ao mesmo tempo que era imposto como a obra de uma elite de vanguarda formada por planejadores, artistas, arquitetos, críticos e outros guardiões de gosto refinado".

Ainda ali, duas posturas distintas se cruzavam no jogo de poder da mercantilização da estética e das aproximações e distanciamentos entre a cultura popular e a de elite. Enquanto Walter Gropius e Le Corbusier, que também mantinham propósitos e conceitos revolucionários, ao implantarem os seus projetos para um homem universal, os impunham de cima para baixo de modo normativo, os dadaístas e os primeiros surrealistas "tentaram mobilizar suas capacidades estéticas para fins revolucionários ao fundir sua arte com a cultura popular" (Harvey, 1992, p. 31), rebelião artística que, anos mais tarde, seria cooptada de modo agressivo pela ideologia liberal (p. 44). 
São particularmente interessantes as reflexões de Choay (1999, p. 72), para quem, desde as intervenções urbanas em Paris do Barão de Haussmann, "a reflexão (não filosófica) sobre a técnica e sua história tende a isolá-la em seu próprio campo enquanto ela está simultaneamente e diretamente implicada tanto na morfogênese do espaço urbano quanto na gênese das mentalidades e dos costumes urbanos".

Relembrando Lefebvre (2000[1974], p. 185), não é apenas das estruturas formais que tratamos. Os materiais, as estéticas, as tecnologias se associam a contextos políticos, econômicos e culturais e "[...] o fato [é] que a 'composição' se inspira em ideologias - que a 'construção' depende de relações sociais - que as técnicas influenciam as proporções, os ritmos, os arranjos espaciais e que elas mudam" 3. A forma urbana, "que figura entre as grandes formas", na interpretação da produção social do espaço, só pode ser compreendida em seu movimento de forma-conteúdo (Lefebvre, 2000[1974], p. 175). Logo, ao refletirmos sobre as tendências do urbanismo, estamos falando, ao mesmo tempo, de técnicas, de economia, de cultura, de ideologias, enfim, de escolhas socioespaciais que revelam a sociedade.

A propósito do período após a Segunda Guerra, Choay (1999, p. 71) afirma: "O postulado do 'espaço objetivo e neutro' foi denunciado. A natureza política e ideológica do planejamento da cidade, ou seja, as escolhas de valores que o fundamentam foram colocadas em evidência".

As concepções do planejamento racionalista e totalizante vão sendo dissolvidas na paisagem urbana pós-anos 1970. No lugar delas tem lugar um mosaico de signos e imagens que encobre a hierarquia bem-comportada da estratificação social por classe da cidade funcional, substituindo-a por uma rede caótica de relações na qual o "individualismo" e o "empreendedorismo" dão o tom (Harvey, 1992). Se, por um lado, os pós-modernos valorizam as diferenças, os múltiplos contextos sociais e a memória histórica, por outro, associados às concepções neoliberais para o planejamento urbano, as referências à tradição ou à identidade tornam-se artifícios superficiais das formas-paisagem a partir de um total ecletismo de estilos e estéticas que fazem da história uma bricolagem. Na produção da nova paisagem urbana, cultura e natureza são mercadorias simbólicas.

Mas, entre o estruturar da modernidade e o simbolizar da pós-modernidade, muitas semelhanças permanecem. Para Habermas (1992), a arquitetura moderna, herdeira do organicismo, do racionalismo e dos movimentos de vanguarda, respondeu bem às necessidades do período pós-guerra, ao juntar forma e função na totalitária cidade funcional. $\bigcirc$ pecado capital da nova construção foi querer impor sua concepção de totalidade a mundos tão diferenciados. A unidade pleiteada pela cidade racionalista se colocou à disposição da organização do espaço promovida pelas limitações econômicas e político-administrativas. Orientada por conexões sistêmicas imprevisíveis, a imposição de malhas, formas e paisagens urbanas ajustadas às funções tomadas como essenciais e universais (morar, trabalhar, ter lazer e circular), foi cega em relação à diversidade das territorialidades sociais e aos distintos mundos da vida (Habermas, 1992). Já não era mais possível defender a não contradição entre modernização capitalista e planificação urbana.

Saltando para o presente, a compreensão da totalidade social não responde mais aos nossos modos de representação, e vice-versa. Como defende Jameson (1996, p. 14), "o modernismo era, ainda que minimamente e de forma tendencial, uma crítica à mercadoria e um

3 Tradução livre da autora. 
esforço de forçá-la a se autotranscender. $\bigcirc$ pós-modernismo é o consumo da própria produção de mercadorias como processo". Ou seja, a ilusão da cultura tornada mercadoria, a mercantilização de tudo, a estetização da realidade, o consumo cultural da experiência alienada e vazia de autenticidade teriam servido à transição ou à modificação sistêmica do próprio capitalismo.

Mas a cultura não é só mercadoria. Reduzir a interpretação da cultura a sua apropriação pelo mercado, como alguns autores o fazem, ao tratarem a cultura como commodity implica uma redução interpretativa. Este olhar é importante para compreender os novos modos de operar do capital, sobretudo a partir da segunda metade do século XX, mas é uma racionalização que nos distancia da interpretação do acontecimento em seu contexto mais amplo (Paes, 2016).

Da monumentalidade inicial à semiótica atual, as paisagens urbanas falam muito sobre nós mesmos e nossa sociedade. Tomando uma inquietação de Jameson (1996, p. 41) como nossa, perguntamos: se as novas paisagens urbanas aterraram o modelo bem-comportado das oposições racionalistas modernas, atravessando as confortáveis dicotomias (novo/velho, global/local, tradicional/moderno), "não será possível afirmar algo semelhante a respeito do modo pelo qual essa estranha superfície nova torna nossos antigos sistemas de percepção da cidade um tanto arcaicos e sem objetivos, sem colocar outro sistema em seu lugar?". Não estaríamos precisando desenvolver uma nova forma de cognição da produção do espaço urbano já revelada em suas paisagens?

Então voltamos à nossa equação, que coloca na mesma fórmula a preservação patrimonial, o desenvolvimento turístico e a renovação urbana. Não é mais possível analisar esses termos separadamente; as paisagens híbridas que estamos criando falam também sobre uma nova forma como vemos e interpretamos o mundo, ou uma nova cognição que vai ganhando forma. Acompanhemos nossas paisagens.

\section{O novo olhar para as áreas centrais urbanas: apontamentos sobre a Amé- rica Latina}

Aqui recortamos esse processo que se deu de forma diferenciada e mais tardiamente, nos anos 1990, na América Latina, onde as intervenções urbanas dos centros históricos refletem muito mais a recuperação das áreas centrais para o consumo cultural, lazer e turismo, do que o retorno das classes médias e das elites para fins residenciais, como ocorreu nos países centrais. Mas, mesmo na América Latina, encontramos traduções diversas desse processo.

Tomando como marco temporal o já citado modelo urbanístico de renovação de Barcelona, na Espanha, sabemos que o patrimônio histórico arquitetônico ganhou um papel de destaque como instrumento de requalificação urbana e gentrificação simbólica, associado a uma nova forma de gestão neoliberal do território, com a entrada das parcerias e dos investimentos dos poderes públicos e de empreendedores privados locais, nacionais e estrangeiros; de órgãos

de comunicação; de grupos sociais organizados e urbanistas de renome internacional, assim como por sua reprodução em série por várias cidades do mundo. A paisagem, de fragmento da totalidade, ganhou maior poder analítico ao representar formalmente esta nova tendência do urbanismo e do processo urbano mundial. 
Respondendo a essa lógica, inúmeras cidades brasileiras e latino-americanas descobriram, nos anos 1990, a refuncionalização turística do patrimônio edificado. No Brasil, inúmeros sítios históricos urbanos, especialmente os sítios coloniais portugueses, ganharam novas cores e funcionalidades na corrida pela atração turística. Os sítios coloniais patrimonializados foram objeto de programas de recuperação das áreas centrais ${ }^{4}$, processo que promoveu, ao mesmo tempo, a regulação do crescimento e do desenvolvimento urbano e turístico de muitas cidades. As exigências e os critérios da Organização das Nações Unidas para a educação, a ciência e a cultura (Unesco) para a apresentação dos dossiês de candidatura a Patrimônio Mundial dos centros urbanos não opõem a preservação à renovação urbana; ao contrário, exigem tais investimentos, configurando uma "coalisão de atores pró-crescimento" (Jacquot, 2012, p. 14).

A cidade de Paraty, município do Rio de Janeiro, com um conjunto arquitetônico colonial com 460 imóveis do século XVIII e do início do XIX na área tombada pelo Instituto do Patrimônio Histórico e Artístico Nacional (Iphan), vem buscando há anos a conquista do título de Patrimônio Mundial, processo bastante ilustrativo para a nossa reflexão. As exigências da Unesco em relação aos seus melhoramentos urbanos, para que a cidade possa ser inserida na Lista, enviam uma mensagem direta: sem desenvolvimento local e renovação da infraestrutura urbana a Unesco não aprova o título de Patrimônio Mundial.

Buscando responder aos critérios da Unesco, Paraty teve que resolver vários problemas de saneamento e conciliar o desenvolvimento urbano, a conservação patrimonial e o turismo: desde 2007, a Prefeitura Municipal aterrou a rede de energia elétrica, retirou das ruas os postes e os cabos de energia, implantou uma iluminação feita por lampiões e luminárias, características do século XVII, e implantou um adequado e moderno sistema de esgotamento sanitário e abastecimento de água potável que beneficiará cerca de $70 \%$ de sua população. Ou seja, os direitos básicos da urbanidade serão estendidos para a sua população, como resposta às demandas do patrimônio cultural e do turismo. Ainda que o uso turístico quase exclusivo do seu Centro Histórico tenha causado uma cisão entre o território da população local nos bairros carentes de infraestruturas, fora do perímetro tombado, e o território dentro do perímetro patrimonializado, essas exigências vindas de fora obrigam a uma readequação do uso do território que favorece a população local, confirmando a indissociação entre a escala local e as demandas globais (Paes, 2015).

Em outro exemplo brasileiro, o Centro Histórico de Salvador, Bahia, declarado Patrimônio Cultural da Humanidade pela Unesco em 1985, é considerado "um dos mais importantes exemplares do urbanismo ultramarino português" (Iphan, [s.d.]d), e foi objeto de um extenso programa de recuperação pelo governo do estado da Bahia, iniciado em

4 Desde os anos 1970, as ferramentas de proteção do patrimônio cultural, no âmbito federal, multiplicaram-se e passaram a constituir políticas integradas entre o planejamento urbano e o turismo. Estão entre as mais importantes: Programa Integrado de Reconstrução de Cidades Históricas (PCH), de 1973 (Secretaria de Planejamento/Iphan/Instituto Brasileiro de Turismo - Embratur); Programa de Revitalização de Sítios Históricos (PRSH), de 1999; Programa Urbis, de 2000 (Iphan); Programa Monumenta, de 2000 (Ministério da Cidade-Minc/Unesco/Banco Interamericano de Desenvolvimento - BID/Iphan); Programas Regionais de Desenvolvimento do Turismo (Prodetur) (Paes, 2015, p. 111). Nos anos 1990, esse processo foi acelerado, particularmente por intermédio dos Minc, com auxilio da Caixa Econômica Federal, do Ministério da Cultura (por intermédio do Iphan) e do Ministério do Turismo, com apoio estrutural e logístico do Embratur, apoio internacional dos Programas da Unesco e verbas do Banco Mundial. O último programa de maior impacto nessa área é a linha de incentivo do governo federal, o Programa de Aceleração do Crescimento - Cidades Históricas (PAC-CH), de 2007, coordenado pelo Iphan e com recursos financeiros destinados a intervenções de restauração e renovação urbana, que selecionou, a partir de 2012, mais de 40 cidades no país, segundo informações do portal do Iphan ([s.d.]b). 
1991. No Programa de Recuperação do Centro Histórico de Salvador, a arquitetura colonial e também a identidade cultural baiana e suas tradições associadas - particularmente as de origem africana, como a musicalidade, a religião e a gastronomia - foram tomadas para a produção de uma nova imagem e um produto turístico mais competitivo nos âmbitos nacional e internacional. As primeiras etapas do Programa mantiveram uma concepção mais fachadista do patrimônio arquitetônico, numa clara valorização formal do conjunto paisagístico.

A população do Pelourinho, sobretudo de pobres e negros, foi direta ou indiretamente expulsa do seu lugar pela apropriação comercial turística. Segundo Nobre (2003, p. 9), após um programa de relocação dos locatários, promovido pelo governo, "do ponto de vista de uso do solo, a maioria dos imóveis foi convertida para o uso comercial (64,8\%), sendo que apenas 16\% deles permaneceram para o uso residencial". Só nos anos 2000, a partir da sétima etapa do Programa de Reabilitação do Pelourinho, a preocupação com a permanência da população que sobreviveu à expulsão apareceu como uma das prioridades do processo. Constatou-se, enfim, que a dinâmica dos centros históricos está visceralmente marcada pela presença de suas populações e que tais áreas não sobrevivem apenas com o uso turístico. Na última etapa da reabilitação foram programados usos mistos para a área, com comércio, residências e equipamentos urbanos funcionais (Berdoulay; Paes, 2008).

O Centro Histórico de São Luís do Maranhão, Patrimônio Mundial desde 1997, fundado pelos franceses em 1612, e um rico conjunto arquitetônico da colonização portuguesa, "reúne cerca de quatro mil imóveis que, remanescentes dos séculos XVIII e XIX, possuem proteção estadual e federal" (Iphan, [s.d.]a). Com um dos maiores acervos de edificações em um único sítio histórico brasileiro, ficou à margem das intervenções da modernização do século XX, fato que o manteve preservado. Contudo, ainda que patrimonializado, a falta de políticas públicas ou o mau uso dessas e de seus recursos o deixaram abandonado, indicando que a simples patrimonialização não é suficiente para incluir o desenvolvimento local em uma agenda global.

Selecionado pelo PAC-CH, não apresentou senão intervenções pontuais. $\bigcirc$ tradicionalismo dos grupos políticos locais, a concentração de renda nas elites, a falta de políticas sociais distributivas e inclusivas, e uma mentalidade conservadora no que se refere à inserção do lugar nas políticas nacionais e nas redes modernas da cultura global são narrativas que insistem nas tramas convenientes da desigualdade social local e em um equivocado isolamento. As premissas do Iphan ([s.d.]c) de "tornar o patrimônio cultural eixo indutor e estruturante na geração de renda, de novos empregos, de agregação social e afirmação identitária das cidades protegidas" não foram aproveitadas para o caso de São Luís do Maranhão.

Vale acrescentar que, no Brasil, o Iphan, fortalecido na última década com a multiplicação de planos, ações, intervenções e orçamento, teve um papel fundamental na visibilidade turística dos nossos centros históricos, fazendo "as vezes" 5 de uma política urbana.

Nesse sentido, e buscando resultados mais exitosos no contexto da América Latina, o Centro Histórico de Quito, Equador, parece ser um bom exemplo: um Centro Histórico vivo, com mais de cinco mil edificações, primeiro Centro Histórico declarado Patrimônio Cultural da

5 Cruz (2000), ao analisar os investimentos em infraestrutura viária e urbana do Prodetur-NE, que, na década de 1990, intencionou equipar e modernizar o território para atrair os investimentos em turismo, afirmou que o turismo estava fazendo "as vezes" de uma política urbana. 
Humanidade da Unesco, em 1978, é um conjunto arquitetônico do século XVII e o maior da América Latina, com 3.2 km² de extensão, a $2.800 \mathrm{~m}$ acima do mar. Em meio a museus, conventos, igrejas, centros culturais e mosteiros, a vitalidade da população local e do pequeno comércio é que preenche as ruas, as praças e as edificações. Ainda sem a influência massiva de turistas a alterar a cotidianeidade, o Programa de Recuperação do Centro Histórico de Quito, com a participação do Governo Nacional, aplicou um modelo de gestão mais inclusivo, com consultas públicas à população local, ao comércio de ambulantes realocados para outros centros, com créditos habitacionais e revitalização dos espaços públicos, afirmando que teve como protagonistas em sua gestão os usuários, os comerciantes e os representantes da população local. Segundo Ana María Armijos, Diretora do Instituto Metropolitano del Patrimonio de Quito, esse projeto foi responsável pela maior regeneração do espaço público urbano e, agora, faz parte do planejamento urbano de Quito em sua totalidade: mobilidade, segurança, equipamentos, serviços de saúde, transporte e comércio, visando uma escala mais humana ${ }^{6}$. Além desse discurso oficial, segundo Martí-Costa, Durán e Marulanda (2016, p. 132), em Quito não se identificou o processo de "volta das elites ao centro", e sim "processos de colonización de nuevas áreas periféricas", além de que as organizações populares de influência indígena andina e as influências locais dos setores médios e das elites fizeram surgir ali uma modernidade urbana diferenciada.

Mas, mesmo ali, parece ser difícil resistir ao formato das demandas externas do turismo, que já começam a pressionar o centro histórico. As intervenções em La Calle de la Ronda e Boulevard - Avenida 24 de Mayo favorecem o uso exclusivo do lazer e do turismo como proteção para os problemas sociais da pobreza na cidade. E Quito também caminha ao encontro desse olhar externo. Sede da Terceira Conferência das Nações Unidas sobre Habitação e Desenvolvimento Urbano Sustentável (Habitat III), em 2016, na entrevista com David Harvey, realizada pelo Comité Popular por Nuestros Territorios - Frente a Habitat III, as principais questões recaem sobre os processos de gentrificação, e David Harvey responde: "No se puede seguir validando el modelo neoliberal actual de desarrollo, donde las urbanizaciones privadas son el objetivo ideal, destruyendo a su paso el espacio público y la calidad de vida urbana" (Marti; Salazar, [s.d.]). Duras afirmações sinalizam o perigo que o modelo de recuperação do Centro Histórico de Quito correrá, ao se inserir na atratividade global dos interesses privados do turismo.

Em Montevideo, Uruguai, o Plan Ciudad Vieja partiu da premissa segundo a qual renovar o velho centro traria ressonância para a renovação da cidade. Como ocorreu em muitos centros no Brasil, em nome da modernização, um grande número de edificações históricas havia sido sacrificado até os anos 1970, quando ainda se considerava a preservação do patrimônio arquitetônico urbano o congelamento da dinâmica das cidades. Com o auxilio da Junta de Andalucía, autoridades e especialistas locais, desde os anos 1990, quando se apresentou o Plan de Ordenamiento Territorial - Plan Montevideo, a Ciudad Vieja já pôde contar com "uma visão integrada, um projeto estrutural e um corpo normativo, incluindo instrumentos de gestão [...] urbana e paisagística [...]" (Intendencia Municipal de Montevideo, 2004, p. 7), visando à democratização do espaço urbano.

6 Dados de uma conferência proferida em 2013 durante o seminário internacional "La intervención urbana en centros tradicionales con un enfoque social", organizado pelo Instituto Francês de Estudos Andinos (CNRS/ MAE) e pela Universidad Externado e realizado em Bogotá, Colômbia. 
Tomando o plano urbanístico como ferramenta para práticas cidadãs, a prioridade aos espaços públicos (parques, praças, festas populares) e às áreas residenciais (moradias populares, autoconstrução e preços viáveis de compra) para todos os estratos sociais foi um projeto exitoso de proteção da população em relação ao mercado imobiliário e aos processos danosos da gentrificação.

Entre cidade e porto, o patrimônio dá forma a novos usos. Palco de muitas transformações, fechamentos e aberturas desde sua ocupação colonial, nos anos 1980 - antes da gentrificação generalizada dos anos 1990 - políticas patrimoniais, de planejamento e gestão urbanas passaram a trabalhar de forma integrada. Nos anos 1990, o "Plan Especial expresa un acuerdo o pacto social acerca de la orientación que debe tomar el desarrollo del territorio" (Intendencia Municipal de Montevideo, 2004, p. 33) em relação à preservação do patrimônio, ao planejamento e ao turismo.

Já o Plan de Ordenamiento Territorial de Bogotá (POT), Colômbia, iniciado em 2000, se insere em um projeto declaradamente mais global, como afirma Beuf (2013, p. 309): "Las políticas urbanas para el centro de Bogotá passaron de ser políticas de recuperación del centro histórico (años ochenta y noventa) a políticas cuyo objetivo es [... p proyectarse en el ámbito de la globalización para consolidar la competitividad urbana de Bogotá en su conjunto".

Ali a reprodução dos mesmos problemas reportados para o Brasil - elitização, remoção de moradores pobres, adequação de equipamentos para a atratividade turística, enfim, gentrificação e fragmentação do tecido urbano estão presentes.

Em Bogotá parece que, na contramão da insegurança social ali instalada, as intencionalidades políticas em relação ao Centro Histórico recaem em sua adequação para um centro competitivo internacionalmente - equação difícil de resolver em relação às demandas locais.

○ Centro Histórico apresenta os elementos arquitetônicos da colonização hispano-americana: a Praça Maior (Praça Bolivar), com a Catedral, o Palácio de Governo, o Palácio da Justiça e a Arcádia Maior (Centro religioso, político e judiciário) e, até os anos 1970, como os outros centros já citados, com exceção de Quito, o Centro Histórico de Bogotá sofreu o abandono ou a destruição da modernização. Com edificações institucionais e moradores tradicionais, várias intervenções de "revitalização" pressionam bairros de moradores tradicionais. Embora um projeto importante de construção de moradias se inclua em suas premissas como renovação urbana, os traços da segregação socioespacial representados pelos diferentes usos são marcantes na área central delimitada.

Como vimos nos centros históricos citados, o próprio selo de Patrimônio Mundial da Unesco funciona como um vetor de desenvolvimento urbano e de atrativo turístico para as cidades. Tal fenômeno, ao mesmo tempo em que pode valorizar a identidade e a economia locais, como vimos em Montevideo e Quito, pode ser fator desarticulador da identidade, ao atrair um número incontrolável de turistas, como ocorre em inúmeras cidades no Brasil, na Colômbia e muitas outras, desde a exemplar Barcelona.

Mas reduzir o turismo a vilão desse processo é uma análise muito simplista, pois patrimônio, turismo e renovação urbana são noções complementares como fenômeno social total, como acentuam Gravari-Barbas, Bourdeau e Robinson (2012, p. 5), e não se conformam a simples relações de causa e efeito. Além de políticas integradas, precisamos de uma cognição mais complexa para compreender a indissociabilidade de tais termos em suas estruturas e dimensões. 


\section{Abrindo novas questões - as paisagens urbanas e a vida em ciclos}

$\bigcirc$ patrimônio cultural, como referência à historicidade do espaço ou, mesmo, como estética e cenarização, revela a apropriação que fazemos do tempo e do espaço no presente. A cultura, hoje, analisada aqui por meio do patrimônio histórico arquitetônico, não é apenas uma amenidade da economia ou uma dimensão menor do conhecimento científico; ela estrutura, em grande medida, o nosso estar no mundo, por isso ela interessa tanto à economia contemporânea. Ela guia a seleção do que tem valor para a sociedade. Como ela está presente em todas as dimensões da vida, a sua apropriação econômica adentrou no campo dos valores simbólicos e invadiu as identidades, os gostos e costumes, criando selos e certificações para os patrimônios materiais, imateriais e naturais. E nossos centros históricos congregam toda essa magia em um só lugar: conjuntos paisagísticos antigos, equipamentos modernos, souvenirs de todo tempo e lugar, gastronomia com sotaques diversos, festas, músicas, danças, experiências únicas que nos fazem, por um instante, esquecer os espaços opacos (Santos, 1996) que ficaram do lado de fora.

Embora a questão da cenografia, a disneyficação, o modelo fachadista ou o estilo patrimônio sejam desafios teóricos e técnicos do urbanismo e da produção do espaço urbano contemporâneo, a apropriação econômica dos bens da cultura não responde a todas as questões. $\mathrm{E}$, nesse contexto, a paisagem como ferramenta analítica e interpretativa revela, em tempo real, a instalação de um novo processo socioestrutural.

Nas cidades latino-americanas, a fragmentação do tecido urbano entre áreas ricas e pobres, entre as infraestruturas concentradas e as áreas abandonadas pelos serviços públicos e pelos interesses privados é muito mais visível na paisagem. A especulação de mercado do solo urbano e os serviços públicos deficitários estão associados a formações socioespaciais (Santos, 1996) originadas na concentração de terras e não nos interesses sociais de uma política distributiva equitativa. As premissas das políticas de produção do espaço urbano são, em grande medida, corretivas e submissas às regras do mercado.

Além disso, a recuperação das antigas áreas centrais ou portuárias apoiou-se, na maior parte dos casos, na refuncionalização turística, elitizando tais áreas em detrimento dos seus moradores pobres e, mesmo, de políticas habitacionais. Espelhando, aos fragmentos, o Modelo de Barcelona, tais cidades também apostaram na construção de edifícios emblemáticos, na captação de eventos ou megaeventos, nos projetos de requalificação, na valorização do uso do solo com consequente especulação imobiliária. Contudo, sem políticas eficazes de inclusão social, as intervenções e a produção de cenários exclusivos para as classes médias e as elites fortaleceram o desenvolvimento desigual preexistente.

Diante desse quadro, é muito importante analisar em cada caso os alinhamentos e os modos de estruturação dos consensos entre atores aparentemente em oposição, e não apenas as oposições entre o preservar o patrimônio, o valorizar o turismo e o renovar o espaço urbano. - problema é estrutural: remete a como a estrutura sociopolítica e econômica dominante se apropria de tais modelos de urbanismo independente dos processos socioespaciais locais, dos seus atores, seus beneficiários e das novas composições territoriais que ganham lugar a partir da submissão, da adequação ou da resistência aos modelos globais. Patrimônio cultural, turismo e renovação urbana são vetores de um mesmo processo de reestruturação do território. Mui- 
tas intervenções urbanas de renovação funcionam como estratégias higienistas, particularmente nos países de desenvolvimento desigual, pois apostam apenas na reprodução de um modelo de urbanismo do ponto de vista formal ou técnico. Por isso, em oposição a um tipo de colonialismo urbano, mediado pelo Estado e por interesses econômicos, o poder local e as resistências sociais têm instrumentos e são resistências úteis frente à gentrificação, processo fortalecido nas organizações sociais para estes três termos: patrimônio cultural, renovação urbana e turismo.

Atualmente, mesmo os centros históricos europeus em contínuo processo de reabilitação para ampliar a atratividade turística estão repensando o excessivo modelo de turistificação, como é o caso, inclusive, de Barcelona, hoje preocupada com as escalas locais para o uso cotidiano de suas populações.

Cabe aqui uma reflexão importante: é possível fazer diferente, usando a mesma receita na renovação em série das paisagens urbanas? Parece que não. A gentrificação se configura, hoje, como um modelo de urbanismo que legitima a expulsão da população de baixa renda de seus locais de moradia, trabalho e identidade, como um padrão de segregação socioespacial elitista que resulta na "creación de espacios aburguesados homogéneos e higienizados, carentes de diversidad" (Alexandri; González; Hodkinson, 2016, p. 25). Mas é preciso compreender que o fenômeno da gentrificação é muito mais amplo do que um modelo de urbanismo. Como afirmam Alexandri, González e Hodkinson (2016, p. 14-15):

El desplazamiento también puede ser el resultado de los actores urbanos globales, como los fondos de inversión que compran activos en problemas, recuperan las viviendas y desplazan los hogares mientras suben los alquileres y los precios de las casas locales; o actores culturales globales (por ejemplo, UNESCO, las Naciones Unidas) que, en colaboración con los gobiernos nacionales y supranacionales (por ejemplo, la UE) declaran centros urbanos o prácticas urbanas como de interés patrimonial o arquitectónico creando brechas de renta que a su vez pueden llegar a desplazar a la población local.

Há um debate acirrado entre cientistas sociais e urbanistas críticos, para os quais a gentrificação é resultado - ou resulta - de injustiças da estrutura social capitalista, enquanto outros, em ressonância às políticas públicas e aos investimentos privados, veem nessas intervenções a recuperação positiva de áreas urbanas abandonadas (Martí-Costa; Durán; Marulanda, 2016, p. 134).

A própria plasticidade do conceito que sobreviveu ao processo de desindustrialização de cidades europeias e norte-americanas e a replicação "em ondas" (Smith, 2006) de processos semelhantes, foram associadas aos objetivos de inversão de capital em cidades com governos neoliberais, ancoradas pela nova forma de incorporar a cultura, o turismo e o meio ambiente ao mercado. Um capitalismo simbólico em ascensão não deixaria nenhum uso cultural, nenhum sentimento sobre a natureza, nenhum desejo de conhecer outros lugares, sem colocar em cada um dos produtos desses derivados um valor econômico.

Então, aquele conceito de gentrificação, ligado à desindustrialização e à "volta ao centro" de moradores abastados, envelheceu. Afirmar que estamos vivendo o mesmo processo que, por difusão ou colonização, chegou aos países do Sul nos anos 1990 não explica tudo. 
A expulsão ou a remoção de classes populares continua. Das classes operárias e de desempregados da indústria às populações de favelas, ocupações irregulares, moradores de rua, indivíduos estigmatizados pela prostituição ou pelo uso de drogas, ou populações que não conseguem mais ali permanecer devido à especulação imobiliária e ao aumento do custo de vida, todos continuam sendo expulsos para dar lugar para as classes médias e elites. "E em todo o planeta, 'revitalizar' espaços 'deteriorados' tem sido um dos principais expedientes na criação de novas 'frentes pioneiras urbanas' para o capital. Estamos imersos na era, por excelência, da cidade como máquina de crescimento (growth machine) [...]" (Souza, 2013, p. 133).

Então não estamos apenas diante de uma "semântica urbana" ou de uma mudança formal da paisagem. A reocupação dos velhos centros urbanos não pode esconder de nós a essência dos conflitos sociopolíticos ali instalados. E a gentrificação não ocorre somente com a recuperação de sítios históricos; há os que defendam o uso dessa concepção para construções novas, para a apropriação de elite de áreas periféricas, urbanas ou rurais, para a revitalização de favelas, entre outras (Martí-Costa; Durán; Marulanda, 2016, p. 135-136).

Do ponto de vista teórico, Morales (2016, p. 217) confronta a crítica exacerbada pós-colonialista que rechaça por completo o uso do termo "gentrificação", devido a considerá-lo apenas "una narrativa estructural proveniente del norte global inaplicable en el sur global". É preciso relativizar ambas as críticas. De um lado, nenhum outro conceito ganhou tamanha força interpretativa para analisar o mesmo processo; então, ainda cabe a sua utilização, mesmo considerando a sua plasticidade no tempo. De outro, não é possível negar que a globalização do processo de gentrificação, hoje, embora com a mesma matriz histórica, é um processo sociopolítico de expressão espacial constituinte do "funcionamiento de la economía política del capitalismo" (Morales, 2016, p. 219). Então, se não podemos aceitar a colonização teórica vinda do Norte, também não podemos descartar o conceito e suas diferentes expressões como as que ocorrem hoje em escala global. É preciso adequar o conceito, aceitando a sua dinâmica desde a sua origem nos anos 1960.

Se aquele processo específico ocorrido em Londres, identificado e nominado por Ruth Glass, não era totalizante, a sua derivação teórica e concreta já bastante alterada nos países do Sul também não é, considerando que são expressões particulares de um mesmo processo que é global. Sua face totalizante é a expressão concreta do funcionamento do capitalismo ou, como afirma Morales (2016, p. 221), "las injusticias de la elitización capitalista de la ciudad" - e isso não podemos perder de vista.

As paisagens que produzimos também nos representam, pois são portadoras de nossa identidade simbólica, patrimônio coletivo de significação histórica e política localizada, fragmento da totalidade do espaço que permite que o tempo, ou a memória, se cristalize, dando-se a nós para interpretação. Tão dinâmica quanto nós, a paisagem é um caleidoscópio imprevisível que nos retrata em formas, subjetividades e simbolismos (Paes, 2016).

Se a expulsão de moradores pobres, a cenarização e a turistificação foram recursos quase exclusivos das políticas públicas e das intervenções privadas em um primeiro momento, atualmente, valorizar os usos tradicionais, habitacionais e a permanência da população mostrou-se, na maior parte dos casos, como uma estratégia essencial para o desenvolvimento local, integrando a preservação do sítio histórico e arquitetônico à sua renovação urbana. 
Na escala internacional, apesar de a Unesco compartilhar da responsabilidade de inserir os bens culturais na esfera global de valores, signos e mercadorias, acirrando a competição entre os países na geopolítica do patrimônio cultural, ela mesma é portadora de critérios que exigem o desenvolvimento local. Na escala local já se reconhece que a preservação de sítios históricos deve ser um processo integrado às políticas públicas setoriais, para garantir a resistência do lugar e melhores condições de vida para moradores, usuários e visitantes.

Como nos apontam Gravari-Barbas e Jacquot (2014), as relações entre turismo e patrimônio, colocadas em foco pela visibilidade dos sítios eleitos como Patrimônio Mundial pela Unesco, expõem também uma nova forma de participação social dos grupos localmente envolvidos, seus consensos e divergências, seus beneficiários e as novas composições territoriais que ganham lugar. Assim, para Gravari-Barbas e Jacquot (2014, p. 33), "o patrimônio mundial está colocado em um pensamento do tipo dialógico, entre preservação e desenvolvimento, o qual não resulta em favor [apenas] de um dos dois termos". E ainda adverte que, embora estar na lista do patrimônio mundial seja um fator favorável ao desenvolvimento, esta posição não é nem necessária, nem suficiente (Gravari-Barbas; Bourdeau; Robinson, 2012, p. 7), como pudemos ver em alguns dos casos expostos.

\section{Considerações finais}

Apesar das contradições apontadas, as visões mais maniqueístas sobre as relações entre patrimonialização, turismo e planejamento urbano não nos deixarão ver as possibilidades que aí residem - são âncoras para refletirmos sobre uma nova forma de desenvolvimento e renovação das cidades. Ao mesmo tempo em que a patrimonialização dos lugares os torna visíveis para o turismo, põe em evidência as suas vulnerabilidades econômicas e socioambientais que deverão ser corrigidas.

A análise desses termos para a interpretação dos processos de gentrificação contemporâneos expressa no espaço urbano um conflito sociopolítico que não pode ser reduzido a uma abordagem economicista, afinal, "[...] la gentrificación está lejos de ser solamente el resultado de fuerzas económicas sobre los barrios. La gentrificación es un conflicto político. Es uno de los procesos más importantes y socialmente injustos que afectan a un número creciente de ciudades hoy en día" (Morales, 2016, p. 235). Ou, nessa mesma linha, como afirmam Alexandri, González e Hodkinson (2016, p. 21): "[...] la gentrificación es una herramienta útil para comprender el desarrollo desigual del capitalismo a nivel planetario. La gentrificación planetaria expone el aumento de la agresividad del poder político y económico del neoliberalismo".

Nem os problemas nem os resultados cabem exclusivamente ao turismo ou ao patrimônio, mas às premissas políticas, culturais e econômicas que podem tomá-los como ferramentas para estratégias mais cidadãs de inclusão social ou não. São escolhas e intenções que essas novas paisagens urbanas escancaram. É bom estarmos atentos para interpretá-las.

\section{Referências}

ALEXANDRI, G.; GONZÁLEZ, S.; HODKINSON, S. Geografías del desplazamiento en el urbanismo de América Latina. Revista INVI - Gentrificación y desplazamientos en América Latina, Chile, v. 31, n. 88, p. 9-25, 2016. 
BERDOULAY, V.; PAES, M. T. D. Imagem e patrimonialização em planejamento urbano: Salvador (Bahia) e Bordeaux em perspectiva. Revista Cidades - Imagens da Cidade, Presidente Prudente, v. 5, n. 7, p. 33-47, 2008.

BEUF, A. Entre competitividad urbana e inclusión social: la producción de la centralidad en el centro de Bogotá y sus impactos territoriales. In: BEUF, A.; MARTINEZ, M. E. (Coord.). Colombia: Centralidades históricas en transformación. Bogotá: Olacchi, 2013. v. 8. p. 309-342.

BORJA, J.; CASTELLS, M. Local y global - La gestión de las ciudades en la era de la información. Madrid: United Nations for Human Settlements, 1996.

CHOAY, F. O reino do urbano e a morte da cidade. Projeto História, São Paulo, v. 18, p. 67-89, 1999.

CRUZ, R. C. Política de turismo e território. São Paulo: Contexto, 2000.

GRAVARI-BARBAS, M.; BOURDEAU, L.; ROBINSON, M. Tourisme et Patrimoine Mondial. Quebec: Presses de l'Université Laval, 2012.

GRAVARI-BARBAS, M.; JACQUOT, S. Introduction - Patrimoine, tourisme, développement. Une triangulation impossible? In:

Patrimoine Mondial et développement au défi du tourisme durable. Quebec: Presses de l'Université du Québec, 2014. p. 1-26.

HABERMAS, J. Modernidade: um projeto inacabado. In: ARANTES, O. B. F; ARANTES, P. E. Um ponto cego no projeto de Jürgen Habermas. São Paulo: Brasiliense, 1992. p. 91-123.

HALL, P. Cidades do amanhã. São Paulo: Perspectiva, 2002[1988]. (Coleção Urbanismo - Estudos).

HAMNETT C. The blind men and the elephant: the explanation of gentrification. Transactions of the Institute of British Geographers, London, v. 16, n. 2, p. 173-189, 1991.

HARVEY, D. Condição Pós-Moderna. São Paulo: Ed. Loyola, 1992.

INTENDENCIA MUNICIPAL DE MONTEVIDEO. Plan Especial Ciudad Vieja. Montevidéu: Intendencia Municipal de Montevideo/Junta de Andalucia/Agencia Espanhola de Cooperación Internacional, 2004.

IPHAN. Instituto do Patrimônio Histórico e Artístico Nacional. Carta de Atenas, nov. 1933. Disponível em: http://portal.iphan.gov.br/uploads/ckfinder/arquivos/Carta\%20 de\%20Atenas\%201933.pdf. Acesso em: 30 dez. 2017.

Centro Histórico de São Luís (MA), [s.d.]a. Disponível em: http://portal.iphan. gov.br/pagina/detalhes/34. Acesso em: 28 dez. 2017.

PAC Cidades Históricas, [s.d.]b. Disponível em: http://portal.iphan.gov.br/pagina/detalhes/235. Acesso em: 28 dez. 2017. 
PAC 2 - Cidades Históricas, [s.d.]c. Disponível em: http://portal.iphan.gov.br/ uploads/ckfinder/arquivos/PAC_2_Cidades_Historicas.pdf. Acesso em: 28 dez. 2017.

Salvador (BA), [s.d.]d. Disponível em: http://portal.iphan.gov.br/pagina/detalhes/241. Acesso em: 28 dez. 2017.

JACQUOT, S. Analyser l'action publique patrimoniale, um triple regard sur la patrimonialisation. In: GIGOT, M. (Coord.). Analyser la patrimonialisation des espaces urbains. Paris: Université François Rabelais, 2012. p. 9-18. Cahier n. 1.

JAMESON, F. Pós-Modernismo - a lógica cultural do capitalismo tardio. São Paulo: Ática, 1996.

LEFEBVRE, H. La production de l'espace. 4. ed. Paris: Ed. Anthropos, 2000[1974].

MARTÍ-COSTA, M.; DURÁN, G.; MARULANDA, A. Entre la movilidad social y el desplazamiento - Una aproximación cuantitativa a la gentrificación en Quito. Revista INVI - Gentrificación y desplazamientos en América Latina, Chile, v. 31, n. 88, p. 131-160, 2016.

MARTI, M.; SALAZAR, M. Entrevista a David Harvey sobre Gentrificación: "Habitat III tiene una posición neoliberal". Resistencia Popular Hábitat 3, [s.d.]. Disponível em: https://resistenciapopularhabitat3.org/2016/07/25/entrevista-a-david-harvey-sobre-gentrificacion-habitat-iii-tiene-una-posicion-neoliberal/. Acesso em: 25 out. 2016.

MORALES, E. L. Acerca de una gentrificación "planetaria" políticamente útil. Revista INVI - Gentrificación y desplazamientos en América Latina, Chile, v. 31, n. 88, p. 217240, 2016.

NOBRE, E. A. C. Intervenções urbanas em Salvador: turismo e "gentrificação" no processo de renovação urbana do Pelourinho. In: ENCONTRO NACIONAL DA ANPUR, 10., 2003, Belo Horizonte. Anais... Belo Horizonte: Anpur, 2003. p. 1-11.

PAES, M. T. D. Cultura, imagens e paisagens. In: JACINTO, R. (Coord.). Transversalidades 2016 - Fotografia sem Fronteiras. 5. ed. Guarda: Centro de Estudos Ibéricos/Câmara Municipal da Guarda, 2016. (Catálogo - Concurso de Fotografia).

. Trajetórias do patrimônio cultural e os sentidos dos seus usos em Paraty (RJ). Resgate - Revista Interdisciplinar de Cultura, Campinas, v. 23, n. 30, p. 105-118, 2015.

Refuncionalização turística de sítios urbanos históricos no Brasil: das heranças simbólicas à reprodução de signos culturais. Geografia, Rio Claro, v. 37, n. 2, p. 319-334, 2012.

PAES, M. T. D.; SILVA, T. C. do N. Estratégias contemporâneas de intervenção urbana e o projeto Porto Maravilha (RJ). Boletim Campineiro de Geografia, Campinas, v. 2, n. 6, p. 345-364, 2016.

SANTOS, M. A natureza do espaço: técnica e tempo razão e emoção. São Paulo: Hucitec, 1996. 
SMITH, N. A gentrificação generalizada: de uma anomalia local à "regeneração" urbana como estratégia urbana global. In: BIDOU-ZACHARIASEN, C. (Coord.). De volta à cidade - dos processos de gentrificação às políticas de "revitalização" dos centros urbanos. São Paulo: Annablume, 2006. p. 59-87.

SOUZA, M. L. de. Semântica urbana e segregação: disputa simbólica e embates políticos na cidade "empresarialista". In: VASCONCELOS, P. A.; CORRÊA, R. L.; PINTAUDI, S. M. (Org.). A cidade contemporânea - segregação espacial. São Paulo: Contexto, 2013. p. 127-146.

VAINER, C. B. Pátria, empresa e mercadoria - notas sobre a estratégia discursiva do Planejamento Estratégico Urbano. In: ARANTES, O.; VAINER, C.; MARICATO, E. (Org.). A cidade do pensamento único: desmanchando consensos. Petrópolis, RJ: Vozes, 2000. p. 75-103.

ZUKIN, S. Paisagens urbanas pós-modernas: mapeando cultura e poder. In: ARANTES, A. A. (Org.). O espaço da diferença. São Paulo: Papirus, 2000. p. 80-103. 